

MAX PLANCK INSTITUTE

FOR DEMOGRAPHIC RESEARCH

Konrad-Zuse-Strasse 1 · D-18057 Rostock · Germany · Tel +49 (0) 3812081 - 0 · Fax +49 (0) 3812081 - $202 \cdot$ www.demogr.mpg.de

MPIDR Working Paper WP 2019-013 I June 2019

Revised May 2020

https://doi.org/10.4054/MPIDR-WP-2019-013

\title{
Mothers' and Fathers' Well-being While Parenting: Does the Gender Composition of Children Matter?
}

Daniela Veronica Negraia I negraia@demogr.mpg.de Jill E. Yavorsky

Denys Dukhovnov

This working paper has been approved for release by: Emilio Zagheni (sekzagheni@demogr.mpg.de),

Head of the Laboratory of Digital and Computational Demography.

(C) Copyright is held by the authors.

Working papers of the Max Planck Institute for Demographic Research receive only limited review. Views or opinions expressed in working papers are attributable to the authors and do not necessarily reflect those of the Institute. 
Mothers' and Fathers' Well-being While Parenting: Does the Gender Composition of Children Matter?

Daniela Veronica Negraia ${ }^{1 *}$, Jill E. Yavorsky ${ }^{2}$, and Denys Dukhovnov ${ }^{3}$

${ }^{1}$ Max Planck Institute of Demographic Research, Rostock, Germany.

${ }^{2}$ University of North Carolina Charlotte, NC, USA.

${ }^{3}$ University of California, Berkeley, CA, USA.

* Corresponding Author: Daniela Veronica Negraia. Mailing Address: Max Planck Institute of Demographic Research, Konrad-Zuse-Straße 1, 18057, Rostock, Germany. Email: negraia@demogr.mpg.de 


\begin{abstract}
Objective: This study examines whether-and if so how-gender composition of children matters for mothers' and fathers' well-being during parenting activities.

Background: Despite that parents interact with girls and boys differently and spend different amounts of time with them, scholars have paid little attention to how gender composition of children may influence parental well-being.
\end{abstract}

Method: The study assessed parental well-being during time spent with children, across four measures of subjective well-being ( $\mathrm{N}=16,140$ activities, 8,621 parents), pooled across three survey waves $(2010,2012,2013)$ from the American Time Use Survey Well-being Module. Random intercept models were used to account for the multilevel structure of the data.

Results: For both mothers and fathers, gender composition of children was not associated with different levels of positive emotions, like happiness or meaning, while parenting. However, for negative emotions, fathers reported greater stress parenting all girls and mixed-gender children (i.e., girl/s and boy/s at the same time) compared to parenting all boys. Mothers reported greater fatigue and stress parenting all girls, compared to parenting all boys. Differences in parenting activities partially explained the stress patterns, for both fathers and mothers.

Conclusion: This study, which is contextualized in broader literature on gender stereotypes, interactional processes and time-use, makes several contributions to research on gender, family, and health and identifies an important factor - gender composition of children - that helps shape mothers' and fathers' well-being while parenting.

Keywords: childhood/children, gender, family roles, parenting, time-use, well-being 


\section{MOTHERS' AND FATHERS' WeLL-BEING: DOES THE GENDER COMPOSITION OF CHILDREN MATTER?}

Understanding mothers' and fathers' subjective well-being is critical because it is linked to physical and mental health outcomes for themselves and their children (Diener, 1994; Diener et al., 2017; Howell et al., 2007). Although most adults have positive attitudes toward parenthood and perceive it as a rewarding life pursuit (Hansen, 2012), research has shown a more complex picture of well-being associated with parenthood. Overall, people describe parenting in a variety of ways, ranging from meaningful and pleasurable to monotonous, stressful, and tiring (Blair-Loy, 2003; Musick et al., 2016; Negraia \& Augustine, forthcoming). More recently, scholars have found differences between fathers' and mothers' emotions during time spent with children, uncovering that mothers experience more negative emotions during child-rearing activities (Musick et al., 2016; Roeters \& Gracia, 2016). However, no research to date has focused on how gender composition of children may influence how parents feel during time with children.

This gap in the literature exists despite the fact that how parents feel during time spent with boys and girls may influence the total time each parent invests in a child. Indeed, a small but growing body of research suggests that child gender influences the amount of time parents, particularly fathers, spend with their children (Lundberg, 2005; Lundberg et al., 2007; Mammen, 2011). For example, both men and women spend more time in certain activities with children who share the same gender (i.e., fathers spend more time with boys; mothers spend more time with girls), though the difference in time investment is much starker for fathers. This previous research raises an important and novel question: do women and perhaps particularly men enjoy their time with same-gender children more than they do with different-gender children? Answering this question could help explain why mothers and fathers spend more or less time with children of different gender compositions.

Using data from the American Time Use Survey (ATUS; 2003-2018) and well-being measures from ATUS's Well-being Module (waves 2010, 2012, and 2013), we examine whether-and if so 
how - the gender composition of their children influences parents' emotional states (feelings of happiness, meaning, stress, and fatigue) during parenting time. Following Musick and colleagues (2016), we define parenting as any activity during which a child was present in the same room as the parent or a child accompanied the parent. In other words, we assess whether parents perceive different emotional rewards or angsts when they interact with girls compared with boys, or with mixed-gender children (i.e., girl/s and boy/s at the same time). We examine how the relationship between well-being and the gender composition of children varies for mothers, and separately, for fathers. Indeed, our focus is not on whether mothers experience greater negative emotions than fathers parenting a particular gender composition of children; but rather, our focus is on whether mothers (and separately, fathers) have greater or worse well-being while parenting mixed-gender children, all girls, or all boys.

Additionally, we examine whether contextual features of parents' time account for any differences in well-being by gender composition of children. For example, because mothers are more likely to include girls, than boys, in more arduous tasks like housework (Lundberg et al., 2007), accounting for this contextual aspect of parenting time in our models could help explain differences in well-being for mothers of girls compared to mothers of boys or to those of mixed-gender children. Lastly, given that different child ages require different parenting strategies (Nomaguchi, 2012)_parenting strategies that may also be gendered — we assess whether the association between gender composition of children and parents' well-being varies across stages of child development.

Our study — which we contextualize in the broader literature on gender stereotypes, gendered interactional processes, and time-use - makes several contributions to research on gender dynamics, family processes, and population health. Our study identifies gender composition of children as an important factor that contributes to mothers' and fathers' emotional well-being while parenting. We also identify variation in this regard by different stages of child development and show that contextual 
features of time help shape how mothers and father fare while parenting children of varying gender compositions.

\section{BACKGROUND}

Despite the rise of women's status in society and increasing similarities in interests among boys and girls (DiPrete \& Buchmann, 2013; Hyde, 2005), child gender still matters for parents. Many parents envision ideal characteristics about the children they hope to raise, which often include preferences for a child's gender or preferences for particular gender compositions of children. Studies using direct evidence (e.g., surveys) show that fathers have a clear preference for boys if they could only have one child (Gallup, 2018), and studies using indirect evidence (e.g., adoption and fertility decisions) suggest that mothers, too, might prefer girls, in cases of having one child (Gibby \& Thomas, 2019). In scenarios of having more than one child, a large share of mothers and fathers prefer mixed-gender children (i.e., at least one boy and one girl), perhaps so that both parents (for different-sex couples) will have access to a child of their similar gender (Gibby \& Thomas, 2019; Nugent, 2013).

These child gender preferences may carry over into the total time parents invest in their children. In fact, a key impetus for this study stems from prior work showing that parents, particularly fathers, spend more time with same-gender children. Previous studies using the 2003-2005 American Time Use Survey found that fathers spend more time solo-parenting, performing childcare, and engaged in leisure when they have sons compared with daughters (Lundberg et al., 2007; Mammen, 2011). Indeed, the presence of a boy in the family appears highly influential on fathers' time, such that fathers also spend more total time with children in families with mixed-gender children than in families with all girls (Mammen, 2011). This same research shows that mothers spend more time in leisure and performing housework with girls than with boys; however, importantly, their time in childcare does not vary by child gender composition (Lundberg et al., 2007; Mammen, 2011). 
Although scholars have examined how child gender - and relatedly gender composition of children - matters for fertility preferences and time-use patterns, this line of work has yet to include a focus on parental well-being. Thus, the current study extends the existing line of scholarship to this new area of inquiry.

\section{PARENTAL WELL-BEING}

Parental well-being has attracted significant scholarly attention in recent decades (for review, see Nomaguchi \& Milkie, 2020). This increased attention is partly due to major shifts in the division of paid and unpaid labor by partnered men and women. Since the 1960s, women's paid employment rates have risen significantly, and men's time in primary childcare has more than doubled (Sayer, 2005). As a result, most partnered couples now split paid and unpaid labor more evenly than a generation ago, even though stark gender inequalities in unpaid labor persist (Negraia et al., 2018; Yavorsky et al., 2015). These changes have caused both men and women to feel mounting pressures to meet family and employment responsibilities (Ruppanner et al., 2019). At the same time, intensive parenting norms have amplified, resulting in new pressures on parents (Hays, 1996; Rizzo et al., 2013). As a result of time constraints and intensive parenting ideals, parents may feel especially strained to meet all of their obligations, especially given that U.S. legislative policies on support for child-rearing have not kept pace with these changes (Ruppanner \& Pixley, 2012).

In the US context, most prior work on parental well-being has relied mainly on single-item assessments of global (i.e., general) well-being, such as “overall” happiness, life-satisfaction, and psychological distress (e.g., depression, anxiety). Generalized measures tend to reflect people's overall self-concept and life circumstances (Kahneman \& Krueger, 2006). Although important, they do not capture affect - a key component of subjective well-being — related to moods, emotions, and feelings (Diener et al., 2017; Kahneman \& Krueger, 2006). More recently, following new developments in wellbeing measures, scholars have begun using experience-based assessments of well-being that are more 
focused on capturing affect and ask respondents how they felt in reference to specific daily activities (in line with prior literature we'll refer to these measures as experienced or momentary well-being; Larson \& Csikszentmihalyi 2014). This approach allows scholars to account for fluctuations in well-being that occur during the day (Negraia \& Augustine, forthcoming) and capture how contextual factors-activity type and presence of others, for example - matter for shaping emotions (McDonnell et al., 2019; Meier et al., 2018; Musick et al., 2016). A key finding of this line of work is that parents report greater happiness and meaning during time spent with their children than without them (Musick et al., 2016); yet, they also rate this time as more fatiguing and stressful (Nelson et al., 2014; Offer, 2016). Empirical investigations exploring potential moderators of these emotions found variation by parental gender and child age. Regarding parental gender, Musick and colleagues (2016) found that compared with fathers, mothers reported greater levels of stress and fatigue and lower levels of happiness during time with children. Likewise, Roeters and Gracia (2016) found that mothers report more stress and less meaning during childcare activities than fathers. Looking at the moderating effect of child age, Meier and colleagues (2018) found that both mothers and fathers report lower levels of happiness while spending time with adolescents (ages 13-17) versus time spent with infants (ages 0 to 2). Mothers also report greater stress and less meaning with adolescents relative to infants, suggesting that mothers' well-being is particularly affected during this developmental age. Researchers, however, have yet to discern how gender composition of children may also matter for parental well-being.

To our knowledge, only one prior study has also considered how gender composition of children may influence parental well-being. Using data from the German Socio-Economic Panel and the British Household Panel Study, Margolis and Myrskylä (2016) examined variation in overall happiness (e.g., "How satisfied are you with your life, all things considered?") by child gender composition. They found that the gender of the first child does not influence parental happiness and the gender composition of children in families with two or more children also has little effect on parental happiness. Studies on 
global well-being are important for understanding people's overall evaluations of their lives. However, general assessments, like the one used in Margolis and Myrskylä (2016), tend to be particularly sensitive to "long-term aspirations, relative position, and notions of what is socially desirable (Kahneman \& Krueger, 2006; National Research Council, 2012)” (Musick et al., 2016, p. 1071). They also do not capture fluctuations in well-being that occur throughout the day (Negraia \& Augustine, forthcoming), including those that could depend on the gender composition of children that a mother/father is parenting.

Building on this prior work, the present study uses assessments of well-being tied to daily activities and empirically tests if the gender composition of children matters for well-being during parenting time. Given that time with children is a critical part of parenting, our focus on men's and women's emotions while parenting captures a useful assessment of their everyday experiences (Krueger et al., 2009).

\section{THEORETICAL FRAMEWORKS}

A large body of research highlights the importance of child gender in shaping parents' attitudes and behaviors more generally, but also their everyday interactions with their children (Chaplin et al., 2005;

Eliot, 2012; Kane, 2012; Lundberg et al., 2007; Mammen, 2011; Mesman \& Groeneveld, 2018). Below, we draw on multiple theoretical perspectives to help explain why parental well-being may vary by gender composition of children.

\section{Gender Matches or Mis-matches Between Parents and Child/ren}

Men's and women's own gender identities may influence how they experience time with children who share either a similar or different gender to their own. Specifically, feelings of sameness with children whose gender matches their own (Starrels, 1994) — for example, fathers believing they are better able to find common ground with their sons in everyday conversations - could lead to more positive emotions while spending time with them. Parents may also derive greater enjoyment or meaning (and/or less 
stress) during time with same-gender children because men and women likely view themselves as "experts" in their respective gender areas (Kane, 2012) and may perceive that their presence is more influential in the development of such children (Leavell et al., 2012). These gendered emotions in parenting could be particularly strong for fathers, given that cultural norms particularly emphasize the importance of fathers in role modeling "manhood" for their sons (Townsend, 2010).

These matching processes may operate similarly in families of mixed-gender children. For example, fathers and mothers may experience heightened positive emotions while simultaneously parenting a boy and girl, because their gender still matches with at least one of the children present. Moreover, prior research suggests that the presence of a same-gender child shapes the interactions to still be focused on gendered activities that culturally align with the parent's gender (Mammen, 2011). For instance, fathers may be more inclined to take their children fishing in families with mixed-gender children than in families with all girls. Thus, feelings of parenting effectiveness and sense of identity may be comparably met in families with mixed-gender children.

\section{Gender-specific Parenting Concerns and Well-being}

Although the rigidity of stereotypes about boys/men and girls/women have loosened in recent decades, gender stereotypes persist (for a review, see Ellemers 2018). Mothers and fathers alter their parenting practices based on their children's gender in many ways, at least two of which could have implications for parents' well-being (Chaplin et al., 2005; Fivush et al., 2000; Hastings et al., 2007; Kane, 2012). First, gender beliefs commonly emphasize girls' fragility and vulnerability (Kane, 2012). Parents may engage in more practices aimed at "protecting" girls' emotional and physical well-being, including controlling girls' movements more than boys' (Eliot, 2012). Heightened vigilance may be tiring or stressful on its own, but it might also be met with resistance from girls, increasing tension between parents and girls. Similarly, gender beliefs and socialization practices that naturalize boys' rowdiness or 
risk-taking (Kane, 2012) could produce stress and fatigue associated with corralling "boys' energy" and/or lead to real behavioral issues with boys.

Second, a growing body of research documents how gendered parenting practices impact the social and emotional development of girls and boys. We argue that these practiced may also impact the well-being of parents. For example, parents of young children attend more to girls' emotional expressions of sadness and anxiety (Chaplin et al., 2005); mothers and fathers use more words related to emotions with girls than with boys (Fivush et al., 2000); and parents more positively reinforce girls' prosocial behavior than boys' (Hastings et al., 2007). If girls are encouraged to exhibit greater pro-sociality and to discuss their feelings more than boys, these behaviors could influence how parents feel during activities spent with children. Girls' greater emotional expressiveness could strengthen parents' relationships with girls, reducing negative emotions and/or increasing positive emotions. Alternatively, parents could feel added stress or fatigue when spending time with girls than with boys, if girls' greater emotional expressiveness results in greater bids for parents' attention or additional emotional labor from parents (Cornwell, 2013). At the same time, parents could interpret child behaviors differently for boys than girls, judging girls more harshly for similar behaviors shown by both genders (e.g., bossy versus leader stereotypes; Kane, 2012; Rudman et al., 2012).

How gender-specific concerns might matter for mothers' and fathers' well-being while parenting mixed-gender children is less clear. On one hand, parenting boys and girls at the same time may reduce some of the gendered concerns we've mentioned, as parents blend their approaches when trying to simultaneously address the needs of boys and girls. On the other hand, some evidence exists that parenting boys and girls at the same time increases gender-differentiating parenting practices, amplifying gender-specific concerns (Kane, 2012). In short, the way that parents socialize their children and navigate gender stereotypes suggests potential implications for parental well-being.

\section{Contexts of Parenting Time and Gender Composition of Children}


Prior research suggests that variation in contextual features of time influence parental well-being (McDonnell et al., 2019; Meier et al. 2018; Musick et al. 2016; McDonnell et al. 2019). We expect this to be particularly true for mothers, whose parenting time in relation to child gender composition, is characterized by less desirable elements (Lundberg et al., 2007; Mammen, 2011). One important contextual dimension of parenting time is activity type. As discussed earlier, prior research suggests that parents' total time investments in their children are gendered (e.g., fathers spend more time with boys; mothers spend more time with girls); relatedly, there is evidence that the types of activities that fathers and mothers engage in with their children may also be gendered ( e.g., parents spend more time with girls in activities seen as feminine, and more time with boys in activities seen as masculine; Chaplin et al., 2005; Kane, 2012; Lundberg et al., 2007; Mammen, 2011). As such, the distribution of activities that parents participate in could influence the angst or joy mothers and fathers experience while parenting. For example, mothers are more likely to incorporate girls than boys in forms of unpaid labor, such as cleaning and shopping (Lundberg et al., 2007), which are associated with higher stress and fatigue and lower happiness and meaning relative to other activities (Musick et al., 2016). Because fathers do less basic childcare in families with girls (i.e., families with all girls, or mixed-gender children), mothers also perform a greater proportion of routine childcare work in these types of families (Lundberg et al., 2007; Mammen, 2011), potentially shaping the stress and fatigue mothers experience while parenting girls. Moreover, fathers are more likely to incorporate boys (including those in mixed-gender families) than girls in fun, low stress activities, like playing (Lundberg et al., 2007; Mammen, 2011). Thus, differences in well-being, if any, may result from the different types of activities in which mothers and fathers incorporate their children depending on whether they have all girls, all boys, or mixed-gender children.

Two other contextual dimensions that may vary based on the gender composition of children and have consequences for subjective well-being are: time spent solo-parenting (i.e., time spent with children, without a second parent present), and amount of and quality of leisure time (Meier et al., 2018; 
Musick et al., 2016). Prior work suggests that solo-parenting time is more demanding and stressful than shared-parenting time (i.e., when another adult, like a partner or spouse, shares in the responsibility of caring for a child; Blair-Loy, 2003; Musick et al., 2016). Also, quality leisure time is key to subjective well-being because it is a time to rest and recover from one's family and work responsibilities (Roeters et al., 2016). Prior studies show that mothers, solo-parent and spend more leisure time with children when they have all girls than only boys, or mixed-gender children, in part because their male partners do less parenting in families that do not include a boy (Lundberg et al., 2007; Mammen, 2011). Thus, parenting girls (versus boys or mixed-gender children) could be more stressful or fatiguing for mothers because they are often doing it alone, or during their limited leisure time (Craig \& Mullan, 2013).

Fathers, too, spend more time solo-parenting same-gender children (i.e., boys; Mammen, 2011). However, the overall time they spend solo-parenting is low (Mammen, 2011) and, thus, the extra soloparenting time they devote to boys (versus girls) may not be consequential for father's well-being. Fathers also spend more leisure time with same-gender children (Mammen, 2011), but they do so in more pleasant activities like sports. Thus, we expect to find few or no differences in fathers' negative emotions by gender composition of children.

\section{The Moderating Effect of Child Developmental Stages}

Different stages of child development are associated with unique parenting challenges and rewards (Luthar \& Ciciolla, 2016; Nomaguchi, 2012). If some of the aforementioned gendered patterns are magnified during certain ages, distinct well-being patterns based on the gender composition of children may emerge across the "arch of child development" (Meier et al., 2018). Two patterns in particular merit further attention.

Parenting young children (ages 0 to 5 years) is a particularly time-intensive and hands-on stage, characterized by round-the-clock childcare work and sleep deprivation, especially for mothers (Yavorsky et al., 2015). To the extent that fathers do less "hands-on" parenting when they have girls 
compared to boys or mixed-gender children (Mammen, 2011), the negative emotions (e.g., stress and fatigue) of mothers parenting girls may be exacerbated during this developmental stage.

Another child developmental stage that might reveal different well-being patterns by gender composition of children is the adolescence stage (ages 13 to 17 years). Even though the care associated with parenting young children is more time-intensive than older children, a consistent finding is that parents' well-being (especially mothers') declines as children age, as measured by global (Luthar \& Ciciolla, 2016; Nomaguchi, 2012) and momentary well-being during time spent with children (Meier et al. 2018; Roeters and Gracia 2016). However, it is possible that only some parents experience lower well-being with adolescents and that previous research—which does not disentangle parents' well-being by child gender composition — has masked differences between parents of all boys, all girls, and mixedgender children. Prior work documents more parent-child conflict in families with adolescent all boys than all girls (Marks et al., 2009), potentially linked to parents' concerns surrounding boys' academic issues or risky behavior (DiPrete \& Buchmann, 2013). At the same time, parents may expect greater adherence to rules and more help with housework chores from adolescent girls than boys (Gager et al., 1999; Livingston, 2019), contexts which may be prone to parent-child disagreements. Finally, families with mixed-gender children may be particularly prone to parent-child dissent because gendered parenting practices are potentially highest in families with mixed-gender children (Kane, 2012; Nugent, 2013), resulting in starker inequalities between teenage children in terms of allowance, housework, and personal autonomy (Gager et al., 1999). In sum, because child developmental stage may impact the association between gender composition of children and parental well-being in unique ways, we include it as a potential moderator in our analyses.

\section{CONTRIBUTIONS OF OUR STUDY}

Based on a representative sample of contemporary Americans, our study makes several critical contributions to the study of family processes, gender dynamics, and population health. First, to our 
knowledge, we are the first to study the direct relationship between parental well-being and children's gender composition using novel measures of subjective well-being tied to daily experiences. In doing so, we examine both positive and negative dimensions of well-being, adding important contributions to a growing body of work documenting relevant factors for parental health. Second, we examine whether the direct relationship between gender composition of children and parental well-being is explained by contextual features of time, such as activity type. We thereby increase understanding of why certain patterns may exist. Third, we examine the moderating role of child developmental stage, in how gender composition of children influences mothers' and fathers' well-being while parenting. Specifically, we build on and extend recent work that documented age-graded changes in parental well-being (Meier et al., 2018; Roeters \& Gracia, 2016) and highlight a subset of parents whose well-being may be particularly disadvantaged during certain child development stages. Overall, our research highlights the need to consider how gender composition of children relates to variation in parental well-being and uncovers multiple distinct, if not surprising, results on this subject.

\section{DATA AND METHODS}

\section{Data}

We pool data across the three cross-sectional waves (2010, 2012, and 2013) of the American Time Use Survey (ATUS) when the Well-being Module was collected. The ATUS, which has been conducted annually since 2003 , is a time-diary study of a nationally representative sample of contemporary Americans, drawn from households in the Current Population Survey (ATUS, 2019; Hofferth et al., 2018). From each household, one person aged 15 or older is randomly selected to be interviewed and asked to recall activities of the previous 24-hour day (4 a.m. to 4 a.m.): "Yesterday [e.g., Monday], at 4:00 a.m. What were you doing?” Next, respondents are asked about the duration of the activity, where it took place, and who was with the respondent. We draw on ATUS's rich time-diary data to: a) identify parenting activities (i.e., activities when parents are in the presence of their children); 
b) capture variation in parenting time across activity types; and c) control for qualitative and quantitative aspects of time with children in our models.

The Well-being module was conducted right after the time-diary interview and asked a subsample of respondents to assess how they felt during three activities, randomly selected from their time-diary, across six dimensions of subjective well-being — happiness, meaning, sadness, stress, pain, and fatigue (Bureau of Labor Statistics, 2017). These data are ideal for our research questions because: a) they provide measures of multiple dimensions of well-being, both positive and negative; and b) their measurement is directly linked to specific daily activities, which then allows us to identify the gender of the child/ren present during these activities, as well as account for contextual factors relevant for wellbeing, like activity type (Kahneman et al., 2004). Notably, we do not merely account for the gender composition of children present in the household, but account for the gender composition of the child/ren present during the activity for which well-being measures are recorded.

\section{Samples}

Pooling the three ATUS survey rounds $(2010,2012,2013)$ when the Well-being Module was conducted yields a sample of 102,796 activities nested within 34,565 men and women. We focus our well-being analysis on respondents with own household children under age $18(\mathrm{~N}=36,298$ activities by 12,189 respondents). We exclude respondents who were themselves ( $\mathrm{N}=13$ respondents), or their spouse/partner $(\mathrm{N}=0$ respondents), under age 18 because being a minor while caring for minor children may be particularly detrimental to one's well-being (Myrskylä \& Margolis, 2014). Because our interest is mainly in parents' time with children, our analyses include only parents who reported well-being in at least one activity with a child present ( $\mathrm{N}=18,198$ activities by 9,301 parents). Finally, in order to capture well-being implications of parenting girls and boys at the same time (i.e., mixed-gender children), we exclude activities in which parents of mixed-gender children were only with child/ren of one gender (i.e., only with girl/s; only with boy/s; $\mathrm{N}=2,058$ activities; representing $7.9 \%$ of the full 
well-being sample, and $20 \%$ of the sample of parents with mixed-gender children). We provide greater details, as well as related robustness checks surrounding this decision, in the "Independent Variables" section.

After these exclusions, the resulting final well-being analytic sample consists of 16,140 activities by 8,621 parents. The father sample includes 5,711 activities by 3,206 fathers. The mother sample includes 10,429 activities by 5,415 mothers. The analysis of well-being reports is conducted at the activity level (i.e., the unit of analysis is the activity).

\section{Key Measures}

Subjective Well-being. Our outcome variables consist of multiple dimensions of subjective well-being. For each of the three sampled activities, respondents were asked to assess how they felt across six dimensions of well-being — happiness, meaning, stress, fatigue, sadness, and pain —using a scale from 0 (did not feel that emotion at all) to 6 (felt that emotion very much; exact script available in the online supplement, Table A-1). These measures, modeled after the Princeton Affect and Time Use Study (Krueger et al., 2009), were designed to capture critical dimensions of affect (Russell, 1980). Although some respondent bias could occur in the recall of their emotional states, research suggests that measures of experienced well-being obtained via 24-hour recall (like in ATUS) are reliable (Kahneman et al., 2004) and provide similar estimates to those obtained via real-time beeper methodologies (Kahneman \& Krueger, 2006).

For this study, we focus on a total of four measures: two of positive affect (i.e., happiness and meaning) and two of negative affect (i.e., stress and fatigue). We model these measures continuously, like previous researchers (Meier et al., 2018; Musick et al., 2016). This approach to focus on four separate measures is theoretically motivated by research showing that parenting is a "mixed-bag" of emotions (Negraia \& Augustine, forthcoming), and people can simultaneously experience both positive and negative emotions in relation to the same activity (Tuccitto et al., 2010). For example, a parent 
bathing a child may feel tired but also happy. Further, although positively correlated (coef. $=0.41$ ), happiness and meaning capture different well-being dimensions: while happiness captures pleasure attainment, meaning captures personal functioning and achievement (Ryan \& Deci, 2001). Similarly, the negative dimensions are positively correlated with each other $($ coef. $=0.35)$, but prior research suggests that they capture different dimensions of negative affect (see Kapteyn et al., 2015; for full correlation matrix, see online supplement, Table A-2). We do not include the measures of pain and sadness, because pain is used mostly in studies of disability, and there is less theoretical basis that sadness might vary by child gender composition.

Parenting Time. Our analysis focuses on variation in parents' well-being by gender composition of children during parenting time. We define parenting as time spent in an activity with own-household child/ren younger than 18 , based on the question "Who was in the room with you? / Who accompanied you?" This question was asked for each time-diary activity (except for sleep and personal activities like cuddling); for detail on the ATUS "Who" files, see online supplement, Table A-3. We focus on parenting time, as opposed to time away from children, because recent work shows that well-being differences between parents and non-parents stem from the stressors and rewards that parents are exposed to during activities when they are performing the parenting role (Negraia and Augustine, forthcoming). In order words, parents' well-being is intimately tied to the time they spend with their children.

Gender Composition of Children. Our main independent variable is gender composition of children during parenting activities. To create this measure, we use information from the ATUS "Who" files, which allows us to identify the gender and age of the child/ren present during the activity. For families with all girls (or all boys) the gender composition of the children present during an activity is 
straightforward because it is necessarily the same as the household roster of children (e.g., if a mother has all girls, then the gender composition of children during any activity is always all girls). However, for families with mixed-gender children, the gender composition of children participating in activities is less straightforward, because parents may interact with boys and girls, at the same time or individually. In our sample, for parents of mixed-gender children, $80 \%$ of reported activities occur with both girls and boys present in the room/accompanying the parent; the remaining $20 \%$ of activities for these parents occur with child/ren of one gender. Because we think being a parent of mixed-gender children is analytically distinct from the experiences of parents of all girls and all boys, we do not recode these $20 \%$ of activities by mixed-gender parents under the parenting "all girls" or "all boys" categories. Instead, we exclude from our analyses the $20 \%$ of activity reports in which parents of mixed-gender children spent time with only one gender (representing $7 \%$ of activities in the full sample), in order to keep the gender composition of children in activity and household roster consistent. In robustness analyses, where we $d o$ recode these activities as we've just described, patterns reported in the main analysis remain.

Child Developmental Stage. To assess if patterns by child gender composition are moderated by developmental stages, we create an indicator for the gender composition and age of child/ren present in the activity using information from ATUS's "Who" files (as mentioned above). We operationalize developmental stages along three stages (0-5 years old or preschool, 6-12 years old or elementary school, 13-17 years old or adolescence). Based on the three child gender composition categories and the three developmental stages, our measure consists of nine mutually exclusive categories: 1 = only girl/s aged $0-5 ; 2=$ only girl/s aged $6-12 ; 3=$ only girl/s aged $13-17 ; 4=$ only boy/s aged $0-5 ; 5=$ only boy/s aged $6-12 ; 6=$ only boy/s aged $13-17 ; 7=$ mixed-gender aged $0-5 ; 8=$ mixed-gender aged $6-12 ; 9=$ mixed-gender aged 13-17. A tenth category capturing activities with children that fell outside these categories (e.g., time with a 5-year-old boy and a 14-year-old boy) was retained in the analysis. 
However, consistent with prior research (e.g., Meier et al., 2018), we do not focus on this group in our description or interpretation of results because our goal is to understand how parental well-being varies by child gender composition during specific developmental stages.

Person- and Activity-level Controls. In all analyses, we control for parents' sociodemographic characteristics (measured at the person level) which prior research has shown to be associated with timeuse patterns (Bianchi et al., 2006; Vinopal \& Gershenson, 2017) and subjective well-being (Hansen, 2012; Nelson et al., 2014; Kapteyn et al., 2015; Riosmena et al., 2017). These characteristics include respondents' age (measured continuously); racial/ethnic group (dummy coded as white non-Hispanic, black non-Hispanic, other non-Hispanic, and Hispanic); whether the respondent is a college graduate (1 = yes, $0=$ no); whether the respondent is enrolled in school $(1=$ yes, $0=$ no $)$; employment status (dummy coded as full-time employed, part-time employed, unemployed, and not working); partnership status $(1=$ spouse or partner in the home, $0=$ no spouse or partner in the home); family income (dummy coded into one of five categories: $<\$ 24,999 ; \$ 25,000-\$ 49,999 ; \$ 50,000-\$ 99,999$; and $>\$ 100,000$ ); and nativity $(1=$ born in the United States, $0=$ not born in the United States). We control for whether the respondent lives in a metropolitan area $(1=$ yes, $0=$ no) because health outcomes vary by place of residence (Eberhardt \& Pamuk, 2004). We account for age of the youngest child in the household, coded into mutually exclusive categories (ages 0-2, infancy and toddlerhood; ages 3-5, preschool; ages 6-12, elementary school; and ages 13-17, adolescence), because child developmental stage structures parents’ time investments and emotions during time with children (Meier et al., 2018; Negraia et al., 2018). Note, in models where we estimate the effect of gender composition of children at specific developmental stages, we no longer control for age of youngest household child. Finally, we account for whether the diary was recorded on a weekday $(1=$ yes, $0=$ no) because parental time demands are, on average, stronger during weekdays than weekends (which could influence parental well-being), and we include 
survey year (dummy coded) to account for period-level effects, which may structure both time-use and well-being.

At the activity level, we account for factors that may affect how the respondent feels about an activity, including: number of own-household children younger than 18 present in the room/accompanying the respondent (measured continuously) because parenting two or more children is likely to require more attention and energy than supervising one child (Musick et al., 2016); duration of the activity (measured in minutes/day) because playing with a child for ten minutes may feel different than doing the same for two hours (Connelly \& Kimmel, 2015); where the activity took place (dummy coded as $1=$ at home, $0=$ somewhere else) because, for instance, eating with children at home may feel different than eating at a restaurant (Meier et al., 2016); and the time of the day when the activity took place (dummy coded as 4:00 a.m. to 8:59 a.m., 9:00 a.m. to 13:59 p.m., 14:00 p.m. to 16:59 p.m., 17:00 p.m. to 20:59 p.m., 21:00 p.m. to 3:59 a.m.) because parenting time may feel more stressful during evening routines compared to earlier times of the day (Campos et al., 2013).

Contextual Aspects of Parenting Time. Based on the theoretical reasons explained earlier, prior work (McDonnell et al., 2019; Meier et al., 2018; Musick et al., 2016), and our own time-use analyses (see online supplement, Table A-5), we construct three contextual measures of parenting time: activity type, solo-parenting, and leisure quantity and quality. Indeed, for all three aspects, our time-use analyses show that gender composition of children influences these contextual features of time for mothers and fathers, and we expect that these aspects could also influence well-being. The activity type measure captures 16 common daily activities (for examples of activities included in each category, see online supplement, Table A-4) and categorizes them into four broad groups: (1) care work (e.g., self-care, adult care, childcare); (2) market work (e.g., work for pay); (3) nonmarket work (e.g., cleaning, cooking, shopping); and (4) leisure (e.g., socializing, relaxing, sports). The solo-parenting measure (minutes/day) captures 
parenting time (i.e., any activity with an own-household child) without a partner or spouse present (McDonnell et al. 2019). The leisure quality measure captures time in leisure (minutes/day), spent: (1) alone, (2) only with adults (i.e., any person 18 years of age or older), (3) only with children (younger than 18), (4) with adults and children present. The leisure quantity measure is the sum of these qualitative measures of leisure (i.e., total time in leisure over the day). We do not account for total time spent sleeping or sleep quality because our time-use analyses reveal no evidence that these time dimensions vary by the gender composition of children, for fathers, or for mothers (see Table A-5 of online supplement).

\section{Analysis Plan}

Our primary aim was to examine whether the gender composition of children is associated with differences in parents' well-being during parenting time. To do this, in Model 1, we included our key independent variable (i.e., gender composition of children in the activity) and full set of person- and activity-level controls. Because our indicator of gender composition of children includes three groups, we first ran the models with "all boys" as the reference group to capture the contrast between "all boys" and "all girls" as well as "all boys" and "mixed-gender children"; we then ran the models with "all girls" as the reference group to capture the contrast between "all girls" and "mixed-gender children." We used random intercept models that account for the multilevel structure of the data (i.e., multiple activities nested within individuals; for more detail and a similar approach, see Musick et al., 2016). This method has been shown to adjust for autocorrelation, unobserved heterogeneity in parents' reports of well-being, nonindependence, and activity-level confounds (Allison, 2009).

We next tested if differences in parents' well-being by gender composition of children are explained by contextual aspects of parenting time. To do this, we took a stepwise approach. We added one contextual aspect at a time to Model 1 (M1), our main model, and then all together, as follows: M1 
+ indicator of activity type; M1 + solo-parenting; M1 + leisure time and leisure quality: M1 + indicator of activity type, time spent in solo-parenting, leisure time and leisure quality.

Lastly, we tested if differences in parents' well-being by gender composition of children are moderated by child developmental stage. To do this, we re-ran Model 1, this time with the indicator of gender composition of children at three different developmental stages (described above) as the independent variable. Next, to assess and visualize which groups were significantly different from one another, we ran post-estimation tests (i.e., contrast and margins Stata commands) and graphed average marginal effects (Esarey \& Sumner, 2018).

All models were estimated separately for mothers and fathers. Note, we do not compare and contrast the results between mothers and fathers. This is because our focus is not on whether mothers, for example, experience greater negative emotions parenting girls than fathers do, but rather whether well-being varies by gender composition of children for mothers, and also for fathers.

The ATUS contains a low amount of missing data, and on few variables $(1.2 \%$ missings on household income, and up to $0.32 \%$ missings on well-being outcomes), making listwise deletion-what we employed - the more parsimonious approach compared with multiple imputation or dummy variables techniques (for discussion on missing data techniques, see Allison, 2003).

\section{FINDINGS}

\section{Samples Descriptives}

Table 1 (below) presents the sociodemographic characteristics for the father and mother samples (for characteristics by gender composition of children, see Table A-6 in the online supplement). Fathers were, on average, 39 years old. About $30 \%$ reported all girls, $34 \%$ reported all boys, and $36 \%$ reported mixed-gender children. Most fathers worked full-time, and lived with a spouse or partner, and over half reported a household income of over $\$ 50,000 /$ year. A larger share of fathers reported having one or two, than three or more, children; about half had a child younger than 6 years; about one third had a college 
education or higher; and a small percentage were enrolled in school at the time of the interview.

Regarding race/ethnicity, the father sample was majority white $(65 \%)$, with Hispanics being the next largest group at $20 \%$.

Mothers were, on average, 36 years old. About 33\% reported all girls, 34\% reported all boys, and $33 \%$ reported mixed-gender children. Over half of mothers were employed (full-time or part-time) and lived with a spouse or partner. Half of the mothers sample reported a household income over $\$ 50,000 / y e a r$. The majority of mothers reported having one or two children (only $22 \%$ reported having three or more children), and about half of mothers had a child younger than 6 years. As for education, about one third of mothers had a college education or higher, with a small minority (7\%) enrolled in school at the time of the interview. Regarding race/ethnicity, the majority of mothers were white at $60 \%$, with Hispanics being the next largest group at $22 \%$.

Table 1. Characteristics of Well-being Study Sample (Means and Percentages) for Fathers and Mothers Participating in Activities with Children - ATUS 2010, 2012, 2013

Subjective Well-being (means; activity level) Happiness

Meaningfulness

Stress

Fatigue

Respondent Characteristics (means and percentages; person level) Age

Gender Composition of Children All Girls

All Boys

Mixed-Gender Children

Racial/Ethnic Group

White Non-Hispanic

Black Non-Hispanic

Other Non-Hispanic

Hispanic

College Degree $(0=$ no; $1=$ yes $)$

School Enrollment $(0=$ no; 1 = yes $)$

Employment Status

Full-time Employed

Part-time Employed

\begin{tabular}{|c|c|}
\hline Fathers & Mothers \\
\hline (1) & (2) \\
\hline 4.84 & 4.79 \\
\hline$(0.72)$ & $(0.75)$ \\
\hline 4.83 & 4.9 \\
\hline$(0.85)$ & $(0.85)$ \\
\hline 1.01 & 1.32 \\
\hline$(0.77)$ & (0.91) \\
\hline 2.12 & 2.58 \\
\hline (0.97) & (1.04) \\
\hline
\end{tabular}

39.21

35.99

(9.42)

$0.30 \quad 0.33$

$0.34 \quad 0.34$

$\begin{array}{ll}0.36 & 0.33\end{array}$

$\begin{array}{ll}0.65 & 0.60\end{array}$

$0.07 \quad 0.11$

$0.07 \quad 0.07$

$0.20 \quad 0.22$

$\begin{array}{ll}0.36 & 0.35\end{array}$

$\begin{array}{ll}0.03 & 0.07\end{array}$

$\begin{array}{ll}0.80 & 0.41\end{array}$

$0.06 \quad 0.20$ 


\begin{tabular}{|c|c|c|}
\hline Unemployed & 0.06 & 0.09 \\
\hline Not Working & 0.07 & 0.30 \\
\hline Spouse/Partner in Household $(0=$ no; $1=$ yes $)$ & 0.94 & 0.75 \\
\hline \multicolumn{3}{|l|}{ Household Income } \\
\hline$<\$ 25 \mathrm{k}$ & 0.14 & 0.23 \\
\hline$\$ 25 \mathrm{k}$ to $49.99 \mathrm{k}$ & 0.22 & 0.24 \\
\hline$\$ 50 \mathrm{k}$ to $99.99 \mathrm{k}$ & 0.36 & 0.31 \\
\hline$\$ 100 \mathrm{k}+$ & 0.27 & 0.21 \\
\hline Income Missing & 0.01 & 0.01 \\
\hline \multirow[t]{2}{*}{ Average Number of Children } & 1.85 & 1.80 \\
\hline & $(0.81)$ & $(0.87)$ \\
\hline One Child & 0.37 & 0.41 \\
\hline Two Children & 0.41 & 0.39 \\
\hline Three/more Children & 0.22 & 0.20 \\
\hline \multicolumn{3}{|l|}{ Age of Youngest Household Child } \\
\hline $0-2$ years & 0.33 & 0.34 \\
\hline $3-5$ years & 0.21 & 0.20 \\
\hline $6-12$ years & 0.33 & 0.31 \\
\hline $13-17$ years & 0.14 & 0.14 \\
\hline N Respondents & 3,206 & 5,415 \\
\hline \multicolumn{3}{|c|}{$\begin{array}{l}\text { Note: Sample of parents reporting at least one activity with own household child/ren younger than } 18 \\
\text { years present. Means are weighted (person-level weights). Ns are unweighted. Estimates for survey year, } \\
\text { weekday, metropolitan area, and region available upon request. Standard deviations in parentheses. }\end{array}$} \\
\hline
\end{tabular}

Our primary aim was to test if parents' positive and negative emotions vary by gender composition of children during activities with children. Table 2 presents random intercept models for fathers predicting subjective well-being in parenting activities. We show only the coefficient for gender composition of children present in the activity (i.e., all girls versus all boys; mixed-gender children versus all boys; and mixed-gender children versus all girls); although all models account for person- and activity-level controls (see Tables A-7 and A-11 of online supplement for coefficients of controls). We found that fathers' positive and negative well-being largely did not differ depending on their children's gender composition (Model 1). The exception was for stress, where fathers of girls reported marginally more stress $(b=.10, p<.10)$ than fathers of all boys (column 5 , Table 2$)$; and fathers of mixed-gender children reported significantly more stress $(b=.13, p<.05)$ than fathers of all boys (column 5 , Table 2 ). These findings suggest that fathers may interpret parenting as more stressful when a girl is present. 
Table 2. Random Intercept Models of Fathers' Well-being during Parenting Time by Gender Composition of Children

\begin{tabular}{cccccccc}
\multicolumn{2}{c}{ Happiness } & \multicolumn{2}{c}{ Meaning } & \multicolumn{2}{c}{ Stress } & \multicolumn{2}{c}{ Fatigue } \\
\hline M1 & M2 & M1 & M2 & M1 & M2 & M1 & M2 \\
\hline$(1)$ & $(2)$ & $(3)$ & $(4)$ & $(5)$ & $(6)$ & (7) & (8)
\end{tabular}

\begin{tabular}{|c|c|c|c|c|c|c|c|c|}
\hline All Girls (Reference: All Boys) & $\begin{array}{l}-0.03 \\
(0.05)\end{array}$ & $\begin{array}{c}-0.03 \\
(0.05)\end{array}$ & $\begin{array}{l}-0.00 \\
(0.06)\end{array}$ & $\begin{array}{l}-0.02 \\
(0.06)\end{array}$ & $\begin{array}{l}0.10+ \\
(0.06)\end{array}$ & $\begin{array}{c}0.09 \\
(0.06)\end{array}$ & $\begin{array}{c}0.02 \\
(0.07)\end{array}$ & $\begin{array}{c}0.02 \\
(0.07)\end{array}$ \\
\hline \multirow[t]{2}{*}{ Mixed-Gender (Reference: All Boys) } & -0.06 & -0.06 & 0.02 & -0.01 & $0.13 *$ & $0.12+$ & 0.01 & -0.00 \\
\hline & $(0.06)$ & $(0.06)$ & $(0.07)$ & $(0.07)$ & $(0.07)$ & $(0.07)$ & $(0.08)$ & $(0.08)$ \\
\hline \multirow[t]{2}{*}{ Mixed-Gender (Reference: All Girls) } & -0.03 & -0.03 & 0.02 & 0.02 & 0.03 & 0.03 & -0.00 & -0.02 \\
\hline & $(0.06)$ & $(0.06)$ & $(0.07)$ & $(0.07)$ & $(0.07)$ & $(0.07)$ & $(0.08)$ & $(0.08)$ \\
\hline N Activities & 5,638 & 5,568 & 5,632 & 5,562 & 5,645 & 5,575 & 5,643 & 5,573 \\
\hline N Respondents & 3,168 & 3,148 & 3,168 & 3,148 & 3,173 & 3,153 & 3,173 & 3,153 \\
\hline Constant & $4.65 * * *$ & $3.88 * * *$ & $4.58 * * *$ & $3.65 * * *$ & $1.42 * * *$ & $1.38 * * *$ & $2.12 * * *$ & $2.54 * * *$ \\
\hline$\sigma_{u}$ & 0.98 & 0.96 & 1.04 & 1.04 & 1.06 & 1.05 & 1.33 & 1.34 \\
\hline$\sigma_{e}$ & 0.92 & 0.89 & 1.20 & 1.14 & 0.99 & 0.99 & 1.16 & 1.15 \\
\hline$\rho$ & 0.53 & 0.53 & 0.43 & 0.45 & 0.53 & 0.53 & 0.57 & 0.58 \\
\hline
\end{tabular}

Note: Coefficients from random intercept models predicting fathers' well-being, measured continuously $(0=$ not at all, $6=$ very much), in activities with at least one own-household child younger than 18. M1 (Model 1) = gender composition of children in activity + individual-level controls + activity-level controls. M2 (Model 2) = M1 + indicator for activity type. To capture the contrast between mixed-gender children and all girls, we change the reference group to "All Girls". Coefficients for control variables are shown in Table A-7 of online supplement. Robust standard errors are shown in parentheses.

To provide a sense of the magnitude of these patterns, we calculated standard deviation effect sizes based on the coefficients from Table 2 and means/standard deviations from Table 1 (Kahneman et al. 2004). Overall, these effect sizes were similar to those found in other research (Meier et al. 2016; Musick et al. 2016). They translated to $13 \%$ of a standard deviation for the difference in stress between fathers of girls and fathers of boys, and $17 \%$ of a standard deviation for the difference in stress between fathers of mixed-gender children and fathers of boys. To provide a more substantive understanding of these effect sizes, we also compared them to those of another central social status: having a residential partner/spouse. Effect sizes related to gender composition of children were $43 \%$ to $56 \%$ as large as the effect sizes related to the well-being of fathers who do not have a residential partner/spouse, compared to those who do.

We next examined if fathers' well-being patterns could be explained by contextual aspects of parenting time. As shown in Model 2 (Table 2, columns 6 and 8), we found that the significance of the stress coefficient declines when we added the indicator of activity type to Model 1 (for both cases 
discussed above), suggesting that this contextual aspect partly explains the relationship between fathers' well-being and gender composition of children. Here, we show only the model with the indicator of activity type (M1 + activity type) because the other models where we added solo-parenting and leisure characteristics did not reveal any change in coefficients compared to Model 1. This suggests that soloparenting and leisure quality and quantity_unlike activity type — do not help explain the relationship between well-being and child gender composition (results for these models available on request).

But, which specific activities or combination of activities help account for father's greater stress with girls (relative to boys) and mixed-gender children (relative to boys)? To answer this question, we used a stepwise approach and added indicators for sixteen discrete activities (the same ones that comprised our measure of activity type), one at a time to our main model (Model 1). The sixteen categories included personal care, care of adults, basic childcare, teaching children, management of children, playing with children, market work, cleaning, cooking, shopping, non-routine housework, relaxing and socializing, sports, eating and drinking, watching television, and education/religion/volunteering (further detail in online supplement, Table A-4). This systematic procedure allowed us to identify three activities that help explain the linkage of stress and parenting for fathers. Table 3 shows that when we controlled for fathers' well-being reports during cleaning, care of adults, and non-routine housework (yard work, home repair), differences in stress during parenting time, for fathers, by gender composition of children were reduced. No other activities had an impact on our model.

Table 3. Random Intercept Models of Fathers' Well-being during Parenting Time by Gender Composition of Children, with Models Controlling for Distinct Activities

\begin{tabular}{lc}
\hline & Stress \\
\cline { 2 - 2 } Model 1 & \\
All Girls (Reference: All Boys) & $0.10+$ \\
Mixed (Reference: All Boys) & $(0.06)$ \\
Model 1 + Cleaning & $0.13^{*}$ \\
All Girls (Reference: All Boys) & $(0.07)$ \\
& \\
& 0.09 \\
& $(0.06)$
\end{tabular}




$\begin{array}{lc}\text { Mixed-Gender (Reference: All Boys) } & 0.13^{*} \\ & (0.07) \\ \text { Model 1 + Care of Adults } & 0.09 \\ \text { All Girls (Reference: All Boys) } & (0.06) \\ & 0.13+ \\ \text { Mixed (Reference: All Boys) } & (0.07) \\ & 0.09 \\ \text { Model 1 + Non-routine Housework } & (0.06) \\ \text { All Girls (Reference: All Boys) } & 0.13+ \\ \text { Mixed-Gender (Reference: All Boys) } & (0.07) \\ & \\ \text { Model 1 + Cleaning + Care of Adults + Non-routine Housework } & 0.09 \\ \text { All Girls (Reference: All Boys) } & (0.06) \\ \text { Mixed-Gender (Reference: All Boys) } & 0.13+ \\ & (0.07) \\ \text { N Activities } & 5,645 \\ \text { N Respondents } & 3,173\end{array}$

Note: Coefficients from random intercept models predicting fathers' well-being, measured continuously $(0=$ not at all, $6=$ very much), in activities with at least one own-household child younger than 18. Models includes child gender composition + individual-level controls + activity-level controls. Here we present coefficients where we also control for types of activity that well-being measures were recorded for: Cleaning with child/ren; Care of adults with child/ren; Non-routine housework with child/ren. Robust standard errors are shown in parentheses.

In supplementary time-use analyses, we found that, overall, fathers did not engage in these three activities for longer (duration) or more often (incidence), with girls than with boys (Tables A-9 and A10 in online supplement). Except for non-routine housework, in which fathers spent more time, and engaged in more often, with boys than with girls. We discuss the implications of these findings in the Discussion section, where we suggest that fathers may qualitatively experience these activities differently when a girl is present versus when only boys are present.

\section{Variation in Mothers' Well-being by Child Gender Composition}

We now turn to the well-being of mothers. We found no significant differences in mothers' positive emotions (happiness and meaning) during parenting time by child gender composition (columns 1 to 4, Table 4). However, for negative emotions, results from Model 1 (columns 5 and 7) show that mothers of all girls reported significantly more stress $(b=.10, p<.05)$ and fatigue $(b=.14, p<.05)$ than mothers of all boys (see Table A-11 of online supplement for coefficients for control variables). We again calculated effect sizes to provide an understanding of the magnitude of these findings. The stress 
disadvantage for mothers parenting all girls, is equivalent to about $11 \%$ of a standard deviation compared with mothers parenting all boys. The fatigue disadvantage for mothers parenting all girls is approximately $13 \%$ of a standard deviation compared to mothers parenting all boys. The effect size for the difference in stress is one third the size of the "effect" associated with a mother not having a residential partner/spouse (compared to having one). The effect size for the difference in fatigue is nearly the same as ( $84 \%$ of) the "effect" of a mother not having a residential spouse/partner.

Table 4. Random Intercept Models of Mothers' Well-being during Parenting Time by Gender Composition of Children

\begin{tabular}{|c|c|c|c|c|c|c|c|c|}
\hline & \multicolumn{2}{|c|}{ Happiness } & \multicolumn{2}{|c|}{ Meaning } & \multicolumn{2}{|c|}{ Stress } & \multicolumn{2}{|c|}{ Fatigue } \\
\hline & M1 & M2 & M1 & M2 & M1 & M2 & M1 & M2 \\
\hline & $(1)$ & $(2)$ & $(3)$ & $(4)$ & $(5)$ & (6) & (7) & $(8)$ \\
\hline All Girls (Reference: All Boys) & $\begin{array}{l}-0.04 \\
(0.04)\end{array}$ & $\begin{array}{l}-0.02 \\
(0.04)\end{array}$ & $\begin{array}{l}-0.04 \\
(0.05)\end{array}$ & $\begin{array}{l}-0.01 \\
(0.05)\end{array}$ & $\begin{array}{l}0.10^{*} \\
(0.05)\end{array}$ & $\begin{array}{c}0.08 \\
(0.05)\end{array}$ & $\begin{array}{l}0.14^{*} \\
(0.06)\end{array}$ & $\begin{array}{l}0.12^{*} \\
(0.06)\end{array}$ \\
\hline Mixed-Gender (Reference: All Boys) & $\begin{array}{l}-0.06 \\
(0.05)\end{array}$ & $\begin{array}{l}-0.05 \\
(0.05)\end{array}$ & $\begin{array}{l}-0.03 \\
(0.06)\end{array}$ & $\begin{array}{l}-0.04 \\
(0.06)\end{array}$ & $\begin{array}{c}0.06 \\
(0.06)\end{array}$ & $\begin{array}{c}0.04 \\
(0.06)\end{array}$ & $\begin{array}{c}0.06 \\
(0.07)\end{array}$ & $\begin{array}{c}0.04 \\
(0.07)\end{array}$ \\
\hline Mixed-Gender (Reference: All Girls) & $\begin{array}{l}-0.02 \\
(0.05)\end{array}$ & $\begin{array}{l}-0.03 \\
(0.05)\end{array}$ & $\begin{array}{c}0.01 \\
(0.06)\end{array}$ & $\begin{array}{l}-0.03 \\
(0.06)\end{array}$ & $\begin{array}{l}-0.04 \\
(0.06)\end{array}$ & $\begin{array}{l}-0.04 \\
(0.06)\end{array}$ & $\begin{array}{l}-0.09 \\
(0.07)\end{array}$ & $\begin{array}{l}-0.09 \\
(0.07)\end{array}$ \\
\hline $\mathrm{N}$ Activities & 10,280 & 10,158 & 10,249 & 10,127 & 10,286 & 10,164 & 10,284 & 10,162 \\
\hline N Respondents & 5,342 & 5,316 & 5,325 & 5,299 & 5,343 & 5,317 & 5,342 & 5,316 \\
\hline Constant & $5.21 * * *$ & $4.61 * * *$ & $4.70 * * *$ & $3.70 * * *$ & $0.83 * * *$ & $0.87 * * *$ & $2.34 * * *$ & $2.67 * * *$ \\
\hline$\sigma_{u}$ & 0.97 & 0.96 & 1.09 & 1.06 & 1.27 & 1.26 & 1.41 & 1.41 \\
\hline$\sigma_{e}$ & 1.05 & 1.03 & 1.27 & 1.21 & 1.18 & 1.16 & 1.27 & 1.25 \\
\hline$\rho$ & 0.46 & 0.47 & 0.42 & 0.43 & 0.54 & 0.54 & 0.55 & 0.56 \\
\hline
\end{tabular}

Note: Coefficients from random intercept models predicting mothers' well-being, measured continuously $(0=$ not at all, $6=$ very much), in activities with at least one own-household child younger than 18. M1 (Model 1) = gender composition of children in activity + individual-level controls + activity-level controls. M2 (Model 2) = M1 + indicator for activity type. To capture the contrast between mixed-gender children and all girls, we change the reference group to "All Girls". Coefficients for control variables are shown in Table A-11 of online supplement. Robust standard errors are shown in parentheses.

Next, we tested if contextual aspects of parenting explain the associations found in Model 1. We found that activity type — but not solo-parenting, leisure time, or leisure quality—reduced the significant, positive relationship between stress and parenting girls (versus boys). We show only the model that has activity type added (Model 2 in Table 4) because the other models showed no change in the stress coefficient when solo-parenting and leisure characteristics were added. Whereas activity type partly accounts for mother's greater stress in parenting girls (versus boys), it does not appear to help explain fatigue differences. For fatigue, the coefficient was reduced slightly, but remained statistically 
significant even after accounting for each of our contextual aspects of parenting time, including activity type (column 8, Table 4).

If activity type helps account for mother's greater stress with girls versus boys, it, again, raises the question of which specific activities are driving this finding. Using the same step-wise approach that we used with fathers, we found that three activities - cleaning, shopping, and personal health care - appeared to be driving higher stress levels among mothers of girls (see Table 5; no other activities had an impact on our model). In supplementary time-use analyses, we investigated if mothers of girls spent more time (duration) or engaged in these activities more often (incidence) than mothers of boys. We found that, indeed, mothers of girls (compared to mothers of boys) reported more activity episodes and spent more time in each of these three activities (see Tables A-12 and A-13 in online supplement). We discuss the implications of these findings in the Discussion section.

Table 5. Random Intercept Models of Mothers' Well-being during Parenting Time by Gender Composition of Children, with Models Controlling for Distinct Activities

\begin{tabular}{|c|c|c|}
\hline & Stress & Fatigue \\
\hline \multicolumn{3}{|l|}{ Model 1} \\
\hline \multirow[t]{2}{*}{ All Girls (Reference: All Boys) } & $0.10 *$ & $0.14 *$ \\
\hline & $(0.05)$ & $(0.06)$ \\
\hline \multirow[t]{2}{*}{ Mixed-Gender (Reference: All Boys) } & 0.06 & 0.06 \\
\hline & $(0.06)$ & $(0.07)$ \\
\hline \multicolumn{3}{|l|}{ Model $1+$ Cleaning } \\
\hline \multirow[t]{2}{*}{ All Girls (Reference: All Boys) } & $0.10+$ & $0.13 *$ \\
\hline & $(0.05)$ & $(0.06)$ \\
\hline \multirow{2}{*}{ Mixed (Reference: All Boys) } & 0.06 & 0.04 \\
\hline & $(0.06)$ & $(0.07)$ \\
\hline \multicolumn{3}{|l|}{ Model $1+$ Shopping } \\
\hline \multirow[t]{2}{*}{ All Girls (Reference: All Boys) } & $0.09+$ & $0.13 *$ \\
\hline & $(0.05)$ & $(0.06)$ \\
\hline \multirow{2}{*}{ Mixed-Gender (Reference: All Boys) } & 0.06 & 0.05 \\
\hline & $(0.06)$ & $(0.07)$ \\
\hline \multicolumn{3}{|l|}{ Model 1 + Personal Health Care } \\
\hline \multirow[t]{2}{*}{ All Girls (Reference: All Boys) } & $0.09+$ & $0.13 *$ \\
\hline & $(0.05)$ & $(0.06)$ \\
\hline \multirow[t]{2}{*}{ Mixed-Gender (Reference: All Boys) } & 0.05 & 0.04 \\
\hline & $(0.06)$ & $(0.07)$ \\
\hline \multicolumn{3}{|c|}{ Model $1+$ Cleaning + Shopping + Personal Health Care } \\
\hline \multirow[t]{2}{*}{ All Girls (Reference: All Boys) } & 0.08 & $0.13^{*}$ \\
\hline & $(0.05)$ & $(0.06)$ \\
\hline \multirow[t]{2}{*}{ Mixed-Gender (Reference: All Boys) } & 0.05 & 0.04 \\
\hline & $(0.06)$ & $(0.07)$ \\
\hline $\mathrm{N}$ Activities & 10,286 & 10,284 \\
\hline N Respondents & 5,343 & 5,342 \\
\hline
\end{tabular}


Note: Coefficients from random intercept models predicting mothers' well-being, measured continuously $(0=$ not at all, $6=$ very much), in activities with at least one own-household child younger than 18. Models includes child gender composition + individual-level controls + activity-level controls. Here we present coefficients where we also control for types of activity that well-being measures were recorded for: Cleaning = cleaning with child/ren; Shopping = shopping with child/ren; Personal health care with child/ren (e.g., personal doctor visits). Robust standard errors are shown in parentheses.

\section{The Moderating Effect of Child Developmental Stage}

We, next, examined if parental well-being patterns by gender composition of children varied when we considered children's developmental stage. To do this, we re-ran our main models with an indicator of gender composition of children (all girls, all boys, and mixed-gender) during three child developmental stages (0-5 years old or preschool, 6-12 years old or elementary school, 13-17 years old or adolescence) as our independent variable. We then graphed the average marginal effects from Model 1.

Fathers. As shown in Figure 1, fathers' positive and negative emotions largely did not differ by their children's gender composition at any developmental stage (margins and cell sizes are reported in online supplement, Table A-14). Supplementary analyses in which we controlled for the contextual aspects of parenting time described above, revealed no change in results (results available upon request). 
Figure 1. Fathers' Well-being by the Gender Composition and Age of Child/Ren Present DURING THE ACTIVITY (MODEL 1).

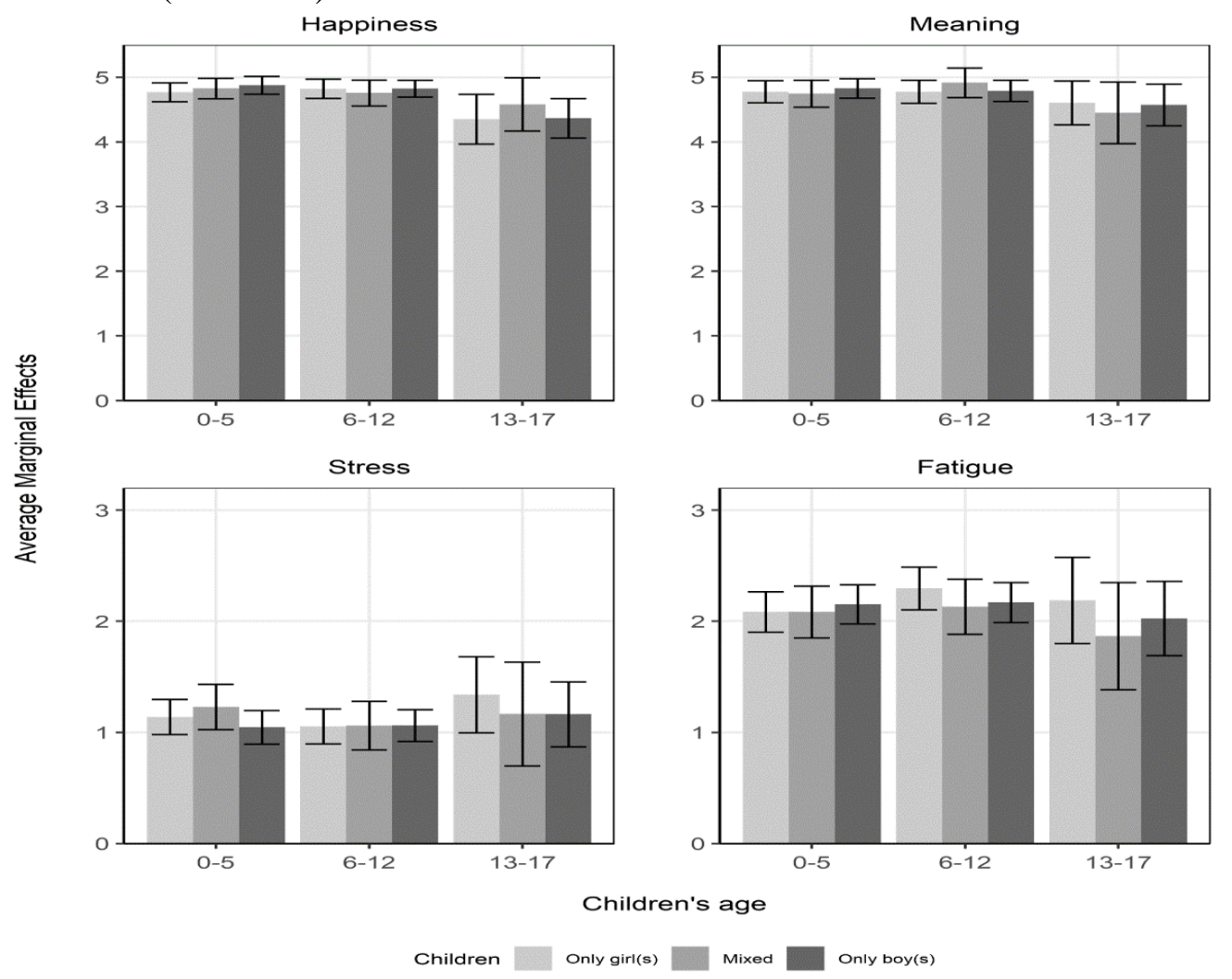

Note: Results present average marginal effects from random effect models (Model 1) predicting emotional well-being of fathers by gender composition and age of child/ren present during the activity. All models control for individual and activity-level factors. Margins and cell sizes are reported in online supplement, Table A-14. Subscripts indicate significant differences between groups at ${ }^{+} p<.10 ; * p<.05$.

Mothers. As shown in Figure 2, mothers' positive emotions (happiness and meaning) during parenting time did not significantly vary based on their children's gender composition at any child developmental stage (margins and cell sizes are reported in online supplement, Table A-15). However, given prior research showing that happiness decreases for mothers when parenting older children (Meier et al. 2018), we investigated this finding further in supplementary analyses. We did so by examining mothers' reported happiness and meaning while parenting the same child gender composition, but different age children (e.g., we compare mothers of girls ages 0-5 to mothers of girls ages 13-17) using random intercept models (see online supplement, Table A-16). We found that mothers parenting adolescents (13-17 years old) experienced significant decreases in meaning and happiness relative to 
mothers parenting young children ( $0-5$ years old), but only for mothers parenting girls and for mothers parenting boys. Indeed, this was not true of mothers parenting mixed-gender children. The stability of positive emotions for mothers parenting mixed-gender children can also be seen in Figure 2, where mothers' positive emotions (especially meaning) while parenting adolescent mixed-gender children remains high. This pattern suggests that previous findings, like those from Meier et al. (2018), are likely driven by mothers parenting single-gender children, either all boys or all girls.

Figure 2. Mothers' Well-Being by the Gender Composition and Age of Child/Ren Present DURING THE ACTIVITY (MODEL 1).



Note: Results present average marginal effects from random effect models (Model 1) predicting emotional well-being of fathers by gender composition and age of child/ren present during the activity. All models control for individual and activitylevel factors. Margins and cell sizes are reported in online supplement, Table A-15. Subscripts indicate significant differences between groups at ${ }^{+} p<.10 ;{ }^{*} p<.05$.

For mothers' negative emotions, we found notable patterns by child developmental stages.

Mothers parenting all girls, aged 0 to 5 years old, reported significantly more fatigue and stress than mothers parenting boys of comparable ages. We also found that during elementary school age (6 to 12 
years), mothers of all girls reported marginally more stress than mothers of mixed-gender children. During adolescence, mothers of all girls and mothers of all boys both reported more stress during parenting compared to mothers of mixed-gender children.

Lastly, we examined whether contextual features of time explain these patterns (not shown, available on request). Similar to our findings in the main analyses, activity type partly explained the negative relationship between well-being and parenting girls ages 0 to 5 years old (relative to parenting boys of comparable ages) for stress but less so for fatigue. When we controlled for activity type-and more specifically, cleaning, shopping, and personal health care - the relationship became insignificant for stress, but not for fatigue. These same three activities also accounted for the greater stress mothers experience parenting girls versus mixed-gender children, ages 6-12. The greater stress that mothers of adolescent girls and mothers of adolescent boys reported, compared to mothers of mixed-gender children, was largely accounted for by shopping and non-routine housework. The inclusion of these two activities significantly reduced the association in both cases.

In sum, our study highlights variation in well-being by gender composition of children, patterns that also vary by child development stages and are partly explained by differences in activities that parents engage in with children.

\section{DISCUSSION}

The daily lives of contemporary American parents are characterized by competing demands for time and attention. Given intensive parenting practices (Hays, 1996; Rizzo et al., 2013) and high levels of workfamily conflict (Blair-Loy, 2003), it is imperative to understand how parents fare emotionally during time with children and identify relevant factors that contribute to their health. We build on and extend previous work on parental well-being (Meier et al., 2018; Musick et al., 2016; Nomaguchi, 2012) by turning attention to a largely overlooked factor — the gender composition of children — and providing several novel results and key contributions in this regard. 
A central contribution of this research is that we uncovered a divergence in how gender composition of children matters for positive, compared to negative emotions. Overall, we found that positive emotions during parenting activities did not vary based on gender composition of children for mothers or fathers. Given that mothers are socialized to view their parenting role as critical regardless of child gender, and because they more equally invest in their children, the finding for mothers is relatively intuitive. For fathers, this finding is more surprising. Fathers invest significantly more time in parenting activities, like childcare, when a boy is present (including when they have mixed-gender children), and strong cultural/gender norms continue to emphasize the importance and efficacy of fathers parenting boys (Kane, 2012; Townsend, 2010). We suggest two potential explanations for this finding. One possibility is that fathers, indeed, feel similar joys when spending time with girls as when spending time with boys (or mixed-gender children). Considering that in recent decades parents have increasingly encouraged girls to pursue stereotypically masculine activities (e.g., sports, science), fathers may feel that they can relate to and effectively parent girls. An alternative explanation is that fathers may report similar positive emotions with girls as with boys because they spend less time with girls. That is, fathers' similar levels of happiness and meaning could be related to them having "lower doses" of parenting girls. However, our analyses controlled for differences in parenting time (i.e., activity duration) by child gender composition, suggesting that the former explanation is more likely. For both mothers and fathers, this is a welcome, and important, null finding that implies that parents experience similar levels of position emotions spending time with all boys, all girls, or mixed-gender children.

However, unlike positive emotions, we found that both mothers and fathers reported greater negative emotions while parenting girls than while parenting boys. Specifically, mothers reported greater stress and fatigue in activities with girls than with boys, and fathers reported greater stress in activities when a girl is present, either when parenting all girls or mixed-gender children. The patterns for stress, appear to be partly explained by differences in activities that fathers and mothers do with girls 
versus boys, or how they experience those activities differently based on child gender composition. Indeed, when we controlled for activity type, the significant positive relationships between stress and mothers' and fathers' time with girls (and father's time with mixed-gender children) reduced in significance. Notably, we do not find that our other contextual aspects of time-solo-parenting or leisure-related characteristics - explain differences in well-being by child gender composition. This could stem from how we measure these two aspects, despite that we follow prior literature in our operationalizations (McDonnell et al., 2019; Musick et al., 2016). Given that we use quantitative measures - like duration of solo-parenting and total time spent in leisure (quantity) and time spent alone in leisure (quality) — our measures may not capture more qualitative features for how these two contextual aspects matter for differences in well-being. Relatedly, how a parent feels while soloparenting, for example, may not change if they parent alone for twenty minutes versus an hour: the experience might be similarly fatiguing and stressful, regardless of the total time spent doing it.

Another unique contribution of this research is that we also identify specific activities that appear to drive differences in negative emotions when girls are present. For fathers, controlling for cleaning, non-routine housework, and care of other adults explains the greater stress in parenting girls and mixedgender children versus boys. Notably, additional analyses show that fathers are not any more likely to incorporate girls or mixed-gender children in these activities. In fact, for non-routine housework activities (e.g., outdoor lawn work), they are actually less likely to include girls than boys. Thus, fathers may experience these activities differently when girls are present. If girls are already more likely to be included in traditionally feminine housework activities (e.g., cleaning) with their mothers, they may be more likely to protest when fathers, too, incorporate them, particularly in forms of non-routine housework that they may view as falling outside of their gender domain. Additionally, during activities like lawn care or home maintenance, fathers may be more likely to express concern about girls' safety in 
helping with work that includes tools or machinery (thereby, heightening their stress levels; Wood \& Eagly, 2012).

For mothers, we found that controlling for shopping, cleaning, and personal health care time explained reports of greater stress parenting girls versus boys. More broadly, these activities induce more negative feelings than more enjoyable activities like playing with one's child, likely because they include forms of unpaid work. In supplementary analyses, we found that, indeed, mothers were more likely to incorporate girls in these activities than boys (both in total time duration and frequency of episodes. This pattern highlights one way in which mothers socialize girls into gendered practices (by which women ultimately come to do more housework in their partnerships), which in turn has negative returns to the well-being of mothers. These findings provide further support to a growing body of work showing that mothers' higher stress in parenting is intimately linked to the gendered nature of the daily activities of mothers (McDonnell et. all. 2019; Meier et al. 2016).

However, it is important to note that activity type does not fully explain the greater stress associated with parenting girls for mothers or parenting girls or mixed-gender children for fathers: either the relationship remained marginally significant, or even when the significance disappeared altogether, the coefficient declined only slightly. Additionally, similar to prior work (McDonnell et al. 2019; Meier et al. 2016), we also found that contextual features of time did not explain gaps in fatigue. Specifically, in our study, we found that the greater fatigue for mothers with all girls (compared with all boys) was not explained by our contextual features of time (including activity type). The remaining unexplained gender imbalance in stress or fatigue during parenting time could result from unobserved contextual factors; and/or interactional differences that occur when a mother spends time with all girls versus at least one boy or all boys. Scholars have suggested that mothers, like fathers, exercise greater vigilance over girls' behaviors than those of boys (Mesman \& Groeneveld, 2018), which could increase parental stress and fatigue. Also, scholars have theorized that girls are socialized to be more prosocial and 
emotive than boys (Hastings et al., 2007). As a result, parents may devote more intellectual and emotional energy to girls, including girls in families with mixed-gender children. Therefore, even if there are simultaneous benefits associated with developing close emotional relationships with girls, these patterns could reduce parental well-being. Finally, fathers, but likely not mothers, may feel less effective at handling girls' emotional and physical needs because of their perceived lower expertise in “girlhood" and femininity (Kane, 2012). This could help explain father's greater stress when parenting girls; it may also contribute to mother's greater stress and fatigue if fathers are more likely to "pass off" the child when they are tired, unwell, or upset. Future research should investigate mechanisms underlying any differences in stress or fatigue between parents of girls and boys.

An additional contribution of the current study is that we assessed whether parental well-being patterns by child gender composition vary across child developmental stages. For fathers, we found little variation in the relationship between gender composition of children and well-being across child developmental stages. Overall, the lack of variation aligns with findings from Meier et al. (2018), which suggest that fathers' well-being is fairly consistent across child developmental stages. We add to this literature and show that fathers' well-being largely does not vary by child developmental stages for different gender compositions either (all boys, all girls, and mixed-gender children).

In contrast, we found greater variation across child development stages in the relationship between gender composition of children and mothers' well-being. Indeed, one of the most striking findings relates to variation in mothers' negative emotions across child developmental stages. The greater stress and fatigue that mothers feel parenting girls compared to boys appears to be driven by the parenting of very young children. And, at least for stress, this is, again, partly explained by activity type in that mothers are more likely to incorporate girls in shopping, cleaning and personal health care. Given the young age, the inclusion of infants or toddlers in these types of activities could make completing these tasks more challenging, or potentially slow them down. 
Notably, we also found that mothers who have adolescent children experience greater stress parenting all girls and all boys compared to those with mixed-gender children. And, in further analyses, we found that only mothers who have single-gender children (all girls or all boys) experience declines in positive emotions (happiness and meaning), relative to their counterparts who were parenting toddlers or infants. Variation in well-being by gender composition for this developmental stage is particularly interesting given other findings that show parents, especially mothers, report lower well-being parenting adolescents than very young children (Meier et al., 2018; Nomaguchi, 2012). Our results indicate that prior findings may be driven by mothers parenting single-gender children, as there appears to be a protecting well-being effect of parenting mixed-gender children. We encourage future studies to investigate potential explanatory mechanisms behind this finding.

Understanding how our results compare to those from studies using general (i.e., global) wellbeing measures is critical, given the extensive use of general well-being measures. Though general wellbeing measures reflect people's overall self-concept and life circumstances (Kahneman \& Krueger, 2006), they are less able to detect fluctuations that might occur in response to contextual factors like the activities in which individuals engage and/or social interactions with their children. Indeed, a key strength of experienced well-being measures, such as the ones used in this study, relative to general assessments, is their ability to capture ebbs and flows associated with parenting. Applying experienced well-being measures allows us to build on the work of Margolis and Myrskylä (2016) and uncover that their key finding- that happiness does not vary by gender composition of children at the aggregate level—also appears to be true for parent's momentary assessments of well-being. Together, by using complementary types of well-being measures, our two studies provide a fuller picture of how parents fare by gender composition of children. At the same time, in comparing our study to that of Margolis and Myrskylä (2016) which focuses on a single happiness measure, we highlight the importance of studying both positive and negative assessments of well-being. Our study is the first, to our knowledge, 
that explores variation by child gender composition for negative emotions. The fact that we found differences in stress and fatigue by child gender composition is important given that negative emotions have been linked to health-related factors, like changes in cortisol and insulin levels that could have broader health implications (for review, see Diener et al., 2017).

Limitations and Directions for Future Research. The ATUS well-being measures allow us to make important contributions to the study of parental well-being. Yet, limitations remain. First, although 24hour recall methodologies as used in ATUS have been shown to produce similar estimates to "real-time" methodologies (Larson \& Csikszentmihalyi, 2014), future research should assess whether our findings hold when people are asked about their well-being while parenting children in "real-time." Replicating this research with multiple types of methodology would be advantageous. Second, future research should also examine how our findings compare when using general assessments of poor well-being (like depression, psychological distress), measures not available in the ATUS. Such research could provide useful information on whether our well-being findings related to stress and fatigue "bubble up" to general negative assessments. Third, because the ATUS are repeated cross-sectional surveys, we do not have measures of well-being at multiple time points during the life course for the same individuals. Therefore, we cannot rule out unobserved heterogeneity that could affect analyses of the relationship between gender composition of children and parental well-being across different stages of child development. Fourth, ATUS does not include information on parents' attitudes regarding gender norms (e.g., traditional, egalitarian gender ideologies) which may also play a role in the linkages between child gender composition and parental well-being (Kane, 2012; Mesman \& Groeneveld, 2018). However, in additional analyses where we explore variation by socioeconomic status (operationalized as highest education level) — a proxy for gender ideology (Mesman \& Groeneveld, 2018), we found that the results presented in our main analysis also apply to parents with a college education or more, and to parents 
with less than a college education (results available on request). Finally, consistent with other research on parental well-being, effect sizes of the well-being gaps between parents with different child gender compositions are modest (Hansen, 2012). However, scientists continue to discuss and develop research on the substantive significance of effect sizes for well-being assessments (Kahneman et al., 2004), and our comparison of the well-being effect of having a residential partner/spouse (versus not) shows that the effects documented here are not negligible. This is consistent with a growing literature which points out that situational contexts are important in shaping emotions (Simon and Nath 2004), as well as evidence that subjective well-being — especially stress - matters for long term health (Diener et al., 2017).

Overall, this study advances the literature on parenthood, well-being, and gender in several ways. Utilizing multiple dimensions of unique well-being measures, we found that gender composition of children appears to matter little for positive emotions for fathers or mothers, but it does matter for negative emotions. For mothers, we also found that significant variation in these well-being patterns exists across child development stages. This work is especially important to consider in relation to other research demonstrating that women's well-being, in particular, takes a hit after parenthood (Musick et al., 2016; McDonnell et al., 2019). We identify a group of mothers - mothers of girls — who may be further disadvantaged in terms of well-being, potentially due to the gendered activities they engage in and to other socialization and interactional processes associated with girls. This study prompts future research to consider seriously the gender composition of children when examining well-being and to uncover mechanisms, in addition to activity type, that contribute to mothers' and fathers' lower wellbeing while parenting particular gender compositions.

\section{REFERENCES}

Allison, P. (2003). Missing Data Techniques for Structural Equation Modeling. Journal of Abnormal Psychology, 112(4), 545-557. 
Allison, P. (2009). Fixed Effects Regression Models. Sage Publications. https://us.sagepub.com/enus/nam/fixed-effects-regression-models/book226025

ATUS. (2019). American Time Use Survey. Bureau of Labor Statistics. https://www.bls.gov/tus/documents.htm

Bianchi, S. M., Robinson, J. P., \& Milke, M. A. (2006). The changing rhythms of American family life. Russell Sage Foundation.

Blair-Loy, M. (2003). Competing Devotions: Career and Family Among Women Executives. Harvard University Press.

Bureau of Labor Statistics. (2014). American Time Use Survey (ATUS) Data Dictionary: 2010, 2012, and 2013 Well-being Module Data Variables Collected in the ATUS Well-being Module. https://www.bls.gov/tus/wbmintcodebk.pdf

Bureau of Labor Statistics. (2017). American Time Use Survey (ATUS) Well-Being Module Microdata Files. https://www.bls.gov/tus/wbdatafiles.htm

Campos, B., Wang, S., Plaksina, T., Repetti, R. L., Schoebi, D., Ochs, E., \& Beck, M. E. (2013). Positive and negative emotion in the daily life of dual-earner couples with children. Journal of Family Psychology, 27(1), 76-85. https://doi.org/10.1037/a0031413

Chaplin, T. M., Cole, P. M., \& Zahn-Waxler, C. (2005). Parental socialization of emotion expression: Gender differences and relations to child adjustment. Emotion (Washington, D.C.), 5(1), 80-88. https://doi.org/10.1037/1528-3542.5.1.80

Connelly, R., \& Kimmel, J. (2015). If You're Happy and You Know It: How Do Mothers and Fathers in the US Really Feel about Caring for Their Children? Feminist Economics, 21(1), 1-34. https://doi.org/10.1080/13545701.2014.970210

Cornwell, B. (2013). Switching Dynamics and the Stress Process. Social Psychology Quarterly, 76(2), 99-124. https://doi.org/10.1177/0190272513482133 
Craig, L., \& Mullan, K. (2013). Parental Leisure Time: A Gender Comparison in Five Countries. Social Politics: International Studies in Gender, State \& Society, 20(3), 329-357. https://doi.org/10.1093/sp/jxt002

Daminger, A. (2019). The Cognitive Dimension of Household Labor. American Sociological Review, 84(4), 609-633. https://doi.org/10.1177/0003122419859007

Diener, E. (1994). Assessing subjective well-being: Progress and opportunities. Social Indicators Research, 31(2), 103-157. https://doi.org/10.1007/BF01207052

Diener, E., Pressman, S. D., Hunter, J., \& Delgadillo-Chase, D. (2017). If, Why, and When Subjective Well-Being Influences Health, and Future Needed Research. Applied Psychology. Health and Well-Being, 9(2), 133-167. https://doi.org/10.1111/aphw.12090

DiPrete, T. A., \& Buchmann, C. (2013). The Rise of Women: The Growing Gender Gap in Education and What It Means for American Schools. Russell Sage Foundation.

Eberhardt, M. S., \& Pamuk, E. R. (2004). The Importance of Place of Residence: Examining Health in Rural and Nonrural Areas. American Journal of Public Health, 94(10), 1682-1686. https://doi.org/10.2105/AJPH.94.10.1682

Eliot, L. (2012). Pink Brain, Blue Brain: How Small Differences Grow Into Troublesome Gaps - And What We Can Do About It. Oneworld Publications.

Ellemers, N. (2018). Gender Stereotypes. Annual Review of Psychology, 69(1), 275-298. https://doi.org/10.1146/annurev-psych-122216-011719

Esarey, J., \& Sumner, J. L. (2018). Marginal Effects in Interaction Models: Determining and Controlling the False Positive Rate. Comparative Political Studies, 51(9), 1144-1176. https://doi.org/10.1177/0010414017730080

Fivush, R., Brotman, M. A., Buckner, J. P., \& Goodman, S. H. (2000). Gender Differences in ParentChild Emotion Narratives. Sex Roles, 42(3), 233-253. https://doi.org/10.1023/A:1007091207068 
Gager, C., Cooney, T., \& Kathleen, T. C. (1999). The Effects of Family Characteristics and Time Use on Teenagers' Household Labor. Journal of Marriage and Family, 61(4), 982-994.

Gallup. (2018). Slight Preference for Having Boy Children Persists in U.S. https://news.gallup.com/poll/236513/slight-preference-having-boy-children-persists.aspx

Gibby, A. L., \& Thomas, K. J. A. (2019). Adoption: A Strategy to Fulfill Sex Preferences of U.S. Parents. Journal of Marriage and Family, 81(2), 531-541. https://doi.org/10.1111/jomf.12541

Hansen, T. (2012). Parenthood and happiness: A review of folk theories versus empirical evidence. Social Indicators Research.

Hastings, P. D., McShane, K. E., Parker, R., \& Ladha, F. (2007). Ready to make nice: Parental socialization of young sons' and daughters' prosocial behaviors with peers. The Journal of Genetic Psychology, 168(2), 177-200. https://doi.org/10.3200/GNTP.168.2.177-200

Hays, S. (1996). The Cultural Contradictions of Motherhood. Yale University Press.

Hofferth, S., Flood, S., \& Sobek, M. (2018). American Time Use Survey Data Extract Builder: Version 2.7 [dataset]. IPUMS. https://doi.org/10.18128/D060.V2.7

Howell, R., Kern, M. L., \& Lyubomirsky, S. (2007). Health benefits: Meta-analytically determining the impact of well-being on objective health outcomes. Health Psychology Review, 1(1), 83-136. https://doi.org/10.1080/17437190701492486

Hyde, J. (2005). The gender similarities hypothesis. American Psychologist, 60(6), 581-592. https://doi.org/doi.org/10.1037/0003-066X.60.6.581

Kahneman, D., \& Krueger, A. B. (2006). Developments in the Measurement of Subjective Well-Being. Journal of Economic Perspectives, 20(1), 3-24. https://doi.org/10.1257/089533006776526030

Kahneman, D., Krueger, A. B., Schkade, D. A., Schwarz, N., \& Stone, A. A. (2004). A survey method for characterizing daily life experience: The day reconstruction method. Science (New York, N.Y.), 306(5702), 1776-1780. https://doi.org/10.1126/science.1103572 
Kane, E. W. (2012). The Gender Trap: Parents and the Pitfalls of Raising Boys and Girls. NYU Press.

Kapteyn, A., Lee, J., Tassot, C., Vonkova, H., \& Zamarro, G. (2015). Dimensions of Subjective WellBeing. Social Indicators Research, 123(3), 625-660. https://doi.org/10.1007/s11205-014-0753-0

Krueger, A., Kahneman, D., \& Fischler, C. (2009). Time use and subjective well-being in France and the US. Social Indicators.

Larson, R., \& Csikszentmihalyi, M. (2014). The Experience Sampling Method. In M. Csikszentmihalyi (Ed.), Flow and the Foundations of Positive Psychology: The Collected Works of Mihaly Csikszentmihalyi (pp. 21-34). Springer Netherlands. https://doi.org/10.1007/978-94-017-90888_2

Leavell, A. S., Tamis-LeMonda, C. S., Ruble, D. N., Zosuls, K. M., \& Cabrera, N. J. (2012). African American, White and Latino Fathers' Activities with their Sons and Daughters in Early Childhood. Sex Roles, 66(1), 53-65. https://doi.org/10.1007/s11199-011-0080-8

Livingston, G. (2019). The way U.S. teens spend their time is changing, but differences between boys and girls persist. Pew Research Center. https://www.pewresearch.org/fact-tank/2019/02/20/theway-u-s-teens-spend-their-time-is-changing-but-differences-between-boys-and-girls-persist/

Lundberg, S. (2005). The Division of Labor by New Parents: Does Child Gender Matter? IZA.

Lundberg, S., Pabilonia Wulff, S., \& Ward-Batts, J. (2007). Time Allocation of Parents and Investments in Sons and Daughters [Working Paper]. US Bureau of Labor Statistics. https://www.researchgate.net/publication/252401196_Time_Allocation_of_Parents_and_Investm ents_in_Sons_and_Daughters

Luthar, S. S., \& Ciciolla, L. (2016). What it feels like to be a mother: Variations by children's developmental stages. Developmental Psychology, 52(1), 143-154. https://doi.org/10.1037/dev0000062 
Mammen, K. (2011). Fathers' time investments in children: Do sons get more? Journal of Population Economics, 24(3), 839-871. https://doi.org/10.1007/s00148-009-0272-5

Margolis, R., \& Myrskyla, M. (2016). Children's Sex and the Happiness of Parents. European Journal of Population, 32(3), 403-420.

Marks, J., Bun, L. C., \& McHale, S. M. (2009). Family Patterns of Gender Role Attitudes. Sex Roles, 61(3-4), 221-234. https://doi.org/10.1007/s11199-009-9619-3

McDonnell, C., Luke, N., \& Short, S. E. (2019). Happy Moms, Happier Dads: Gendered Caregiving and Parents’ Affect. Journal of Family Issues, 0192513X19860179. https://doi.org/10.1177/0192513X19860179

Meier, A., Musick, K., Fischer, J., \& Flood, S. (2018). Mothers' and Fathers’ Well-Being in Parenting Across the Arch of Child Development. Journal of Marriage and Family, 80(4), 992-1004. https://doi.org/10.1111/jomf.12491

Meier, A., Musick, K., Flood, S., \& Dunifon, R. (2016). Mothering Experiences: How Single Parenthood and Employment Structure the Emotional Valence of Parenting. Demography, 53(3), 649-674. https://doi.org/10.1007/s13524-016-0474-X

Mesman, J., \& Groeneveld, M. G. (2018). Gendered Parenting in Early Childhood: Subtle But Unmistakable if You Know Where to Look. Child Development Perspectives, 12(1), 22-27. https://doi.org/10.1111/cdep.12250

Musick, K., Meier, A., \& Flood, S. (2016). How Parents Fare: Mothers' and Fathers' Subjective WellBeing in Time with Children. American Sociological Review, 81(5), 1069-1095. https://doi.org/10.1177/0003122416663917

Myrskylä, M., \& Margolis, R. (2014). Happiness: Before and after the kids. Demography, 51(5), 18431866. https://doi.org/10.1007/s13524-014-0321-x 
Negraia, D., \& Augustine, J. (forthcoming). Unpacking the Parenting Well-Being Gap: The Role of Dynamic Features of Daily Life across Broader Social Contexts. Social Psychology Quarterly.

Negraia, D., Augustine, J. M., \& Prickett, K. C. (2018). Gender Disparities in Parenting Time Across Activities, Child Ages, and Educational Groups. Journal of Family Issues, 0192513X18770232. https://doi.org/10.1177/0192513X18770232

Nelson, S. K., Kushlev, K., \& Lyubomirsky, S. (2014). The pains and pleasures of parenting: When, why, and how is parenthood associated with more or less well-being? Psychological Bulletin, 140(3), 846-895. https://doi.org/10.1037/a0035444

Nomaguchi, K. M. (2012). Parenthood and Psychological Well-Being: Clarifying the Role of Child Age and Parent-Child Relationship Quality. Social Science Research, 41(2), 489-498. https://doi.org/10.1016/j.ssresearch.2011.08.001

Nomaguchi, K., \& Milkie, M. A. (2020). Parenthood and Well-Being: A Decade in Review. Journal of Marriage and Family, 82(1), 198-223. https://doi.org/10.1111/jomf.12646

Nugent, C. N. (2013). Wanting Mixed-Sex Children: Separate Spheres, Rational Choice, and Symbolic Capital Motivations: Wanting Mixed-Sex Children: Three Motivations. Journal of Marriage and Family, 75(4), 886-902. https://doi.org/10.1111/jomf.12046

Offer, S. (2016). Free Time and Emotional Well-Being Do Dual-Earner Mothers and Fathers Differ? Gender \& Society, 30(2), 213-239. https://doi.org/10.1177/0891243215596422

Riosmena, F., Kuhn, R., \& Jochem, W. C. (2017). Explaining the Immigrant Health Advantage: Selfselection and Protection in Health-Related Factors Among Five Major National-Origin Immigrant Groups in the United States. Demography, 54(1), 175-200. https://doi.org/10.1007/s13524-016-0542-2 
Rizzo, K. M., Schiffrin, H. H., \& Liss, M. (2013). Insight into the Parenthood Paradox: Mental Health Outcomes of Intensive Mothering. Journal of Child and Family Studies, 22(5), 614-620. https://doi.org/10.1007/s10826-012-9615-z

Roeters, A., \& Gracia, P. (2016). Child Care Time, Parents' Well-Being, and Gender: Evidence from the American Time Use Survey. Journal of Child and Family Studies, 25(8), 2469-2479. https://doi.org/10.1007/s10826-016-0416-7

Roeters, A., Mandemakers, J. J., \& Voorpostel, M. (2016). Parenthood and Well-Being: The Moderating Role of Leisure and Paid Work. European Journal of Population, 32(3), 381-401. https://doi.org/10.1007/s10680-016-9391-3

Rudman, L. A., Moss-Racusin, C. A., Phelan, J. E., \& Nauts, S. (2012). Status incongruity and backlash effects: Defending the gender hierarchy motivates prejudice against female leaders. Journal of Experimental Social Psychology, 48(1), 165-179. https://doi.org/10.1016/j.jesp.2011.10.008

Ruppanner, L., Perales, F., \& Baxter, J. (2019). Harried and Unhealthy? Parenthood, Time Pressure, and Mental Health. Journal of Marriage and Family, 81(2), 308-326. https://doi.org/10.1111/jomf.12531

Ruppanner, L., \& Pixley, J. E. (2012). Work-to-Family and Family-to-Work Spillover: The Implications of Childcare Policy and Maximum Work-Hour Legislation. Journal of Family and Economic Issues, 33(3), 283-297. https://doi.org/10.1007/s10834-012-9303-6

Russell, J. A. (1980). A circumplex model of affect. Journal of Personality and Social Psychology, 39(6), 1161-1178. https://doi.org/10.1037/h0077714

Ryan, R. M., \& Deci, E. L. (2001). On happiness and human potentials: A review of research on hedonic and eudaimonic well-being. Annual Review of Psychology, 52, 141-166. https://doi.org/10.1146/annurev.psych.52.1.141 
Sayer, L. C. (2005). Gender, Time and Inequality: Trends in Women's and Men's Paid Work, Unpaid Work and Free Time. Social Forces, 84(1), 285-303. https://doi.org/10.2307/3598304

Starrels, M. (1994). Gender Differences in Parent-Child Relations. Journal of Family Issues, 15(1), 148165. https://doi.org/10.1177/019251394015001007

Townsend, N. (2010). Package Deal: Marriage, Work And Fatherhood In Men's Lives. Temple University Press.

Tuccitto, D. E., Giacobbi, P. R., \& Leite, W. L. (2010). The Internal Structure of Positive and Negative Affect: A Confirmatory Factor Analysis of the PANAS. Educational and Psychological Measurement, 70(1), 125-141. https://doi.org/10.1177/0013164409344522

Vinopal, K., \& Gershenson, S. (2017). Re-Conceptualizing Gaps by Socioeconomic Status in Parental Time with Children. Social Indicators Research, 133(2), 623-643. https://doi.org/10.1007/s11205-016-1370-x

Watson, D., Clark, L. A., \& Tellegen, A. (1988). Development and validation of brief measures of positive and negative affect: The PANAS scales. Journal of Personality and Social Psychology, 54(6), 1063-1070.

Wood, W., \& Eagly, A. H. (2012). Chapter two-Biosocial Construction of Sex Differences and Similarities in Behavior. In J. M. Olson \& M. P. Zanna (Eds.), Advances in Experimental Social Psychology (Vol. 46, pp. 55-123). Academic Press. https://doi.org/10.1016/B978-0-12-394281$4.00002-7$

Yavorsky, J. E., Kamp Dush, C. M., \& Schoppe-Sullivan, S. J. (2015). The Production of Inequality: The Gender Division of Labor Across the Transition to Parenthood. Journal of Marriage and Family, 77(3), 662-679. https://doi.org/10.1111/jomf.12189 